\title{
Emiliano Ilardi, Dalla Strada alla finestra
}

\section{Marco Stupazzoni}

\section{(2) OpenEdition}

\section{Journals}

\section{Edizione digitale}

URL: http://journals.openedition.org/studifrancesi/9277

DOI: 10.4000/studifrancesi.9277

ISSN: 2421-5856

\section{Editore}

Rosenberg \& Sellier

\section{Edizione cartacea}

Data di pubblicazione: 1 juin 2008

Paginazione: 207

ISSN: 0039-2944

Notizia bibliografica digitale

Marco Stupazzoni, «Emiliano Ilardi, Dalla Strada alla finestra», Studi Francesi [Online], 154 (LII | I) | 2008 , online dal 30 novembre 2015, consultato il 10 janvier 2021. URL: http://journals.openedition.org/ studifrancesi/9277 ; DOI: https://doi.org/10.4000/studifrancesi.9277

Questo documento è stato generato automaticamente il 10 janvier 2021.

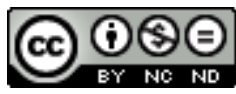

Studi Francesi è distribuita con Licenza Creative Commons Attribuzione - Non commerciale - Non opere derivate 4.0 Internazionale. 


\title{
Emiliano Ilardi, Dalla Strada alla finestra
}

\author{
Marco Stupazzoni
}

\section{NOTIZIA}

EMILIANO ILARDI, Dalla Strada alla finestra, in Il Senso della posizione. Romanzo, media e metropoli da Balzac a Ballard, Roma, Meltemi, 2005 («Nautilus». Collana diretta da Alberto Abruzzese), pp. 43-110.

1 A partire dall'Ottocento, le relazioni tra romanzo e rappresentazione dello spazio urbano assumono un rilievo particolarmente profondo in relazione alla nuova morfologia della città intesa come microcosmo pubblico per eccellenza che detta le regole dei nuovi rapporti sociali. Attraverso l'analisi di due romanzi-chiave della Comédie humaine, quali Le Père Goriot e Illusions perdues, Ilardi affronta in questo denso capitolo lo studio della Parigi balzachiana, di quel luogo, cioè, attraverso cui lo scrittore rende chiaramente percepibili al lettore «una molteplicità di campi che si trovano tra loro in una relazione dialettica» (p. 56). Si tratta, puntualizza l'autore, di relazioni non più rigide e date una volta per tutte, ma «instabili e in continuo cambiamento» ed è proprio questa nuova forma di percepire i rapporti sociali a costituire «il motore della narrazione balzachiana» (p.54). Soltanto uno spazio mobile e in trasformazione (uno spazio, ad esempio, come la pension Vauquer) è in grado di produrre eventi che modificano lo stato presente delle cose e poter essere trasformati in narrazione. Nel caso di Lucien, le tensioni proprie del suo desiderio di integrarsi, come protagonista, nel mondo parigino coincidono perfettamente con le possibilità che la città gli offre; ed è in questo, osserva l'autore, che percepiamo il grandioso tentativo di Balzac: «trasferire la virtualità dell'immaginazione tipica del soggetto moderno allo spazio sociale in modo che non ci sia più conflitto» (p. 68). Attraverso i codici della morale, del consumo e del successo, Lucien legge, interpreta e assimila l'oscuro e impenetrabile linguaggio della metropoli restringendo lo sguardo a pochi luoghi ed esclusivamente alla loro superficie. In questo senso, il personaggio balzachiano «non si limita a 
osservare il contesto urbano, vuol farne parte, vuole arrivare; arrivare a possedere tutto ciò che gli offre Parigi; assumere tutte le forme che via via la metropoli gli presenta; essere in tutti i luoghi e svolgere tutti i mestieri che gli capitano; realizzare ogni fantasticheria» (p. 73). 